\title{
MORIR DE AMOR ${ }^{1}$
}

\author{
Diana de $\mathrm{Paco}^{2}$
}

(Una cama de matrimonio. MIRIAM se incorpora. Es una mujer de unos 50 años. Parece feliz, ilusionada. Amanece).

Miriam.- Cariño, ha sido una noche maravillosa. Cariño, es tan bonito estar contigo, aquí, escondidos, protegidos de todo. Ayer estuviste fantástico. Mucho mejor que mi marido. ¿Estuve yo mejor que tu mujer? ¡No es broma! Ahora somos... amantes, ¿cómo dijiste? Oficiales. Por eso hay que comparar, a ver si lo hemos conseguido.

Cariño, además esta noche no has roncado, ni una sola vez, después de... ya sabes, te quedaste "durmiendito", así, y hasta ahora. Cómo te quiero después de follar, cariño. Mucho más que antes de hacerlo. ¿Tú sientes que me quieres después de hacerlo mucho más que antes? Yo sé que sí, cariño. A lo mejor es solo una impresión. Pero es muy agradable, cariño... ¡Qué lindo estás cuando duermes sin hacer ruido, es la primera vez que te veo dormir así, como un angelito del cielo! Esta noche no has roncado, mi vida.

Mira, mira qué bigotito más precioso que tienes. A las mujeres modernas del siglo XXI no les gustan los hombres con bigote, pero a mí sí, cariño. El tuyo. El tuyo me gusta porque es bonito y blandito. El de mi marido no me gusta, pica y me irrita la piel porque es del tipo Chevrón. ¡Qué risa lo de Chevrón! Ya te conté...

\footnotetext{
${ }^{1}$ Fecha de recepción: 07/05/2014.

Fecha de aceptación: 01/07/2014.

2 Diana de Paco comienza su carrera como dramaturga en 1999 con Eco de Cenizas, Accésit al Premio de Teatro Universidad de Sevilla 1998, y desde entonces no ha parado de escribir y de llevar a escena numerosas obras: Polifonía (finalista al Premio Calderón de la Barca 2000), Lucía y La Antesala (Premio al mejor libro de Murcia -teatro- 2002), Su tabaco, gracias (2004), Obsession Street (Premio Palencia de Teatro 2008), El canto póstumo de Orfeo. Monólogo de tres almas (2009), PCP (2010), El monominimalista, Ana y Manuel (2011), De mutuo acuerdo (2012), Espérame en el cielo... o mejor no (2013), etc. Asímismo es Profesora Titular de Universidad en el área de Filología Griega, Departamento de Filología Clásica, Universidad de Murcía, España; $₫$ didepaco@um.es.
} 
¿Sabes? He escuchado una noticia, ay que me da la risa, he escuchado una noticia de una mujer que..., me muero de la risa. Tenía las tetas muy gordas, le pesaban entre las dos $40 \mathrm{~kg}$, ¿te lo imaginas? Mira que yo las tengo gordas, y como tú dijiste ayer noche, que estabas encantador, parecen de una joven de veinte años y no de una mujer de... bueno, y tantos más de cincuenta, huy, no me importa decir mi edad. Desde ayer ya no me importa. Todo lo que ha pasado me ha hecho subir la autoestima muchísimo. Tengo 55 años y los llevo muy bien. Bueno, pues esta chica intentó asfixiar a su marido metiéndole la cabeza entre los pechos mientras hacían el amor. ¿Te imaginas? ¡Huy qué risa me da! ¡Ella dice que era la forma más dulce de matarlo! Es que me parto de risa cariño... Mira, mira... (Hace el gesto de apretarse los pechos con los brazos), ¿se empalmaría? El marido, digo, mientras se asfixiaba... La verdad es que, en cierto modo, la chica tenía razón, si tenía que morir, mejor entre los pechos, ¿no? En la cama... Como os gusta a los hombres. ¿Y esa otra de Brasil? Huy, cariño, aquella brasileña que se puso veneno en el..., aquí, en el...., cariño en el chi... en el poto... En el coño, cariño, para que él se envenenara mientras... ya sabes... ¡Hay que ver qué ideas! También ésta... le podía haber dado una infección ahí bajo... A mí estas cosas no se me ocurrirían, yo soy muy simple para esto... (Lo mira. Le toca la cara).

Qué bigote más bonito. Es mucho mejor que el que tiene mi marido. Ese es del tipo Chevron, ya te digo, lo he leído en la revista del avión. El bigote define la personalidad del hombre, el de tipo Chevron dice que es el preferido de los hombres gordos con complejo de superioridad y con otra cosa que... no lo he entendido, porque estaba en inglés. Sí, cariño mío, tendría que haber aprendido inglés si al final me iba a venir contigo a vivir aquí, pero qué iba a saber yo, si ayer vine pensando que era para romper definitivamente... Yo no me imaginaba que todo iba a cambiar, que ibas a dar el paso y a convertirte en mi amante oficial... que ahora como amantes oficiales la cosa iba a cambiar, eso no me lo podía imaginar, hasta ayer. (Coge el recorte de la revista). Mira, aquí está, le pedí a Javier, Javier, el azafato que te dije, el que va a concursar en gran hermano, ya te lo dije que era muy simpático, y guapo, desde luego, pero bueno, eso es lo de menos porque yo si estoy contigo ya así, no voy a mirar a otros hombres. Pero ayer no sabía esto, bueno pues le pedí a Javier la hoja de la revista, con la explicación del 
bigote y de la personalidad, mira que la suya... Hombre gordo, espera, te lo voy a leer: (Lee el inglés como está escrito). Beloved by fat men with superiority complexes and medallion-wearing lotharios, esto último no sé muy bien lo que es, que se compran medallones con lo que ganan en la lotería o algo así, dijo Javier, tipo escapulario, ¿a quién se le ocurre? Será una horterada de oro, como precisamente la que lleva el gordo de mi marido, que también tiene el complejo de superioridad, jes verdad lo de los bigotes! Y me dijo: "vente que te enseño un medallion que se dejó un pasajero una vez". Yo, como soy muy simple, me lo creí y me fui con él. Me pareció divertido. Nos metimos en la cabina y allí, sólo nos morreamos, cariño, porque yo no sabía que tú habías cambiado, si no, ni eso. Javier fue muy simpático, desde el principio y, cuando me enseñó el medallion, me miró y, oye, una atracción bestial, nos tuvimos que besar un poco, así con lengua, solo un poco, para aliviar la tensión sexual que era brutal, cariño. Javier me cautivó por su simpatía y buen humor, que no es habitual en los asistentes de vuelo hoy en día, y un poquito por su juventud, pero eso es lo de menos. Es que Javier me dijo que azafato resultaba ofensivo, ahora son asistentes de vuelo. Es un chico con un sentido del humor... ya al entrar dijo: "Bienvenidos al vuelo... destino París", y se puso a reír porque todo el mundo se empezó a alarmar porque donde veníamos era aquí, a Londres. ¿Te lo puedes creer? ¡Qué gracioso! Besaba muy bien, pero no llegamos a hacer mucho más. Dice que me va a llamar, pero si entra en Gran Hermano y se hace famoso, seguro que luego se olvida de mí. Eso pensé yo ayer y se lo dije, así sin más, y él me contestó que no, que él era muy fiel y que la fama no le iba a cambiar. Claro, yo le dije todo eso porque mi historia contigo estaba rota y sólo venía a confirmarlo porque yo no sabía que tú querrías que fuéramos amantes oficiales y todo esto (Mira el recorte).

Mira, hay también bigote fumanchú y bigote cepillo de dientes, pero el suyo, el de mi marido, sin duda es el Cabrón, bueno es Chevrón, pero yo estuve bromeando con Javier, que si éste (Señala uno de los de la revista) era el bigote que mi marido lleva y que no es Chevrón, es Cabrón... Pues eso, mientras Javier me metía mano nos reíamos de la ocurrencia. Sólo me toco un poco por aquí y por allá, porque como yo creía que tú no ibas a cambiar y que venía para dejarlo definitivamente... Fue muy gracioso, cariño, porque estábamos en la cabina, ¡con el piloto! y mientras él conducía el avión me metía 
mano Javier y nos besábamos y decíamos entre risas que el bigote era el modelo Cabrón y no Chevrón. Y cuando me quité las bragas, empezaron las turbulencias, y pienso que fue porque el piloto se excitó mucho y entonces nos pidió que nos pusiéramos más cerca para que pudiera disfrutar más y eso hicimos, ¡sin pensarlo! Entonces como yo iba sin bragas el piloto con una mano me tocaba el culo, mientras que Javier me besaba y me tocaba por aquí y por allá, ¿te imaginas la escena? Y, claro, pues las turbulencias aumentaban y entonces entró el sobrecargo a ver qué pasaba y nos pilló allí a los tres... ya sabes y se quedó pasmado y le explicamos lo del bigote y ya pues nos dejó seguir, le hizo gracia, cerró la puerta pero yo creo, cariño, que se quedó con las ganas de unirse al grupo, pero claro yo ya no tenía espacio libre donde tocar y además alguien se tenía que hacer cargo del duty free que ya era casi la hora de pasar con el carrito. ¡Qué bien me lo pasé, cariño! A ver, que no hicimos nada malo, unos tocamientos ingenuos porque yo pensaba que venía para que lo dejáramos y no para que nos reconciliáramos, si lo llego a saber... Javier me dio el teléfono, me dijo que estaría por aquí hasta el jueves, pero claro, yo en estas circunstancias no voy a llamarlo, porque si tú me demuestras que de verdad todo va a ser diferente, yo prefiero estar contigo (Pausa, se recompone. Lo mira. Piensa).

Es que ayer, cuando llegamos, me dio la sensación de que no eras tú. No sé por qué, no me follabas violentamente, como otras veces, me hacías el amor. Sentí que me moría. Precisamente ayer te tuviste que convertir en mi amante oficial. Es verdad, cariño, que hasta ahora yo había estado muy descontenta con mi marido. Es verdad que tú me has hecho mucho sufrir, con esas manitas tan largas que tienes, que se te van con mucha rapidez sin razón alguna, y mira que luego al último momento cuando yo ya quería terminar con todo, vienes tú y me dices que quieres ser mi amante oficial, que todo va a cambiar, que estarás conmigo siempre. ¿Qué es un amante oficial? No es ni un marido, ni un amante esporádico. Me dices. Es una pareja estable que proyecta un futuro sin angustias, ni miedo al compromiso pero sin terceras personas. ¿Y esa definición? La psiquiatra, ya decía yo, pero bueno, si te ha ayudado, bien venida sea la psiquiatra. ¿Cómo se puede cambiar así, de la noche a la mañana, sin avisar? Y tan convencido, incluso cuando te insinué, así por encima, sin entrar en detalles, la travesura del avión, pero vamos que no te conté ni la mitad de lo que ahora te estoy contando y sólo con pensarlo que te 
excitaste, ¡qué fuerte, cariño! Que se te puso dura y me echaste un polvo que... no, eso no era un polvo, cariño, eso era hacer el amor. Mucho mejor de lo que me lo ha hecho mi marido siempre, dónde va a parar, espero que tú me hayas disfrutado más que a tu mujer. Yo creo que sí. ¡Se puede cambiar! Eso me dijiste, me sonaba a terapia, pero por qué no probar... (Para. Reflexiona. Se da cuenta, en parte, de lo que está diciendo. Se muda su rostro).

En otros tiempos me hubieras dado un puñetazo, un hostión como tú le llamas, si sólo te llego a insinuar que me ha gustado un poco el asistente de vuelo, pero ayer... ayer te encantó, que te excitaste mucho... (El teléfono no suena). Huy, el teléfono. Es Javier, cariño, como le dije que lo íbamos a dejar... Pero bueno, no lo cojo y ya está. Pobre, mira cómo insiste, no sé si contestar y decirle que al final nos vamos a dar otra oportunidad, que anoche estuviste fenómeno y que ni siquiera has roncado, que tienes el bigote mucho más bonito que el Cabrón Chevrón de mi marido...

Otra vez, cómo insiste, pobrecillo, no sé si cogerlo cariño. Si no, lástima de hijo, va a estar todo el rato probando y no nos va a dejar disfrutar del primer día de nuestra nueva vida. Javier tiene unas cosas... bueno te cuento, te cuento todo, si además, ya vi que te gustaba: Pues nada, lo que te dije estuvimos ahí en la cabina, metiéndonos mano por aquí y por allá delante del piloto hasta que aterrizamos. Luego parecía que el toque de corneta que indica que el aterrizaje ha sido exitoso con aplausos de los pasajeros y todo, estaba dedicado a nosotros y a nuestra hazaña. Me invitó a una cerveza, como tenía tiempo hasta que tú llegaras le dije que sí, no era cuestión de irme corriendo después de lo que había pasado. ¡Tan gracioso! Nos sentamos en el bar del aeropuerto y Javier entonces siguió metiéndome mano por debajo de la mesa. Yo le dije "quita... deja... que dentro de poco me tengo que ir", pero no paraba. ¡Qué divertido! Nos reímos. Él dijo que la falta de presión nos había excitado, que eso pasa y que no se puede evitar, pero que también influía lo atractiva que yo era... Yo estaba un poco nerviosa pero encantada con todo lo que estaba sucediendo y, claro, muy excitada, tengo que reconocerlo y, de pronto, miro al frente y veo que se acerca... ¡el piloto!, despacio, fijando su vista debajo de la mesa, mientras Javier tenía sus manos entre mis piernas, ¡sí cariño!. Se le veía todavía... ya sabes, calentito, por el aterrizaje tocándome el culo, lo noté al fijarme en sus pantalones mientras 
se acercaba, se paró frente a mí, sin decir nada y Javier, cariño, seguía ahí dale que te pego... El piloto me cogió la cara con las dos manos y me dio un beso en la boca despacio, con lengua y todo, muy bonito, sí señor, me hacía cosquillas todo el cuerpo por dentro... luego esbozó una sonrisa muy pequeñita y se fue. Cariño, ¿a que parece un sueño? Ahora sí te lo he contado todo, bueno, casi todo. Es todo tan extraño, pero claro si es la presión entonces ya entiendo mejor que no nos pudiéramos controlar. Cariño, cuando vi al piloto venir hacia mí casi pensé que se iba a sentar con nosotros y a tocarme el culo otra vez aunque esta vez las bragas no me las había quitado, pero no, sólo me dio un beso en la boca, esbozó la sonrisa y se fue. ¡Qué viaje, cariño! Para que luego digan que los vuelos low cost son los peores...

(El teléfono no suena). Cariño, lo voy a coger, si no, te va a despertar el teléfono y estás durmiendo tan a gusto, y sin hacer esos ruidos de siempre, que parecías un cerdo al que estaban descuartizando y mira ahora, como un angelito... Cariño, ¿cómo se puede cambiar tanto? ¿Cómo? ¡Esa psiquiatra es un fenómeno! Habrá que ver si sigues así, pero yo ya lo sabía, que cuando uno se lo propone, cuando uno se lo propone, aunque sea con ayuda profesional, consigue lo que quiere. Yo he confiado en eso todos estos años ( $E l$ teléfono no suena, ella atiende un segundo). Lo cojo, así no te pones celoso, lo cojo ahora y ya le digo que no quiero seguir con él porque se irá a Gran Hermano y me olvidará, es para no hacerle daño diciéndole que es que todo ha cambiado entre nosotros y que tú y yo vamos a ser amantes oficiales (Contesta al teléfono que NO ha sonado). ¿Qué? Javier, por favor, no puedo hablar mucho él está aquí, conmigo. ¿Lo de las almendras? Sí, Javier, lo he intentado pero no he sido capaz. Javier, él, ha cambiado, me quiere. Ha hecho terapia, ¿sabes? Me ha pedido perdón, me ha dicho que estaremos siempre juntos, sin su mujer, sin mi marido, nosotros dos como amantes oficiales... No, no puedo hacerlo. Te recordaré siempre, Javier. Y, cuando te vea en Gran Hermano, marcaré tu número para votarte con mi móvil, todas las veces que me dejen, te apoyaré Javier, pero tú eres muy joven, tienes toda una vida por delante y yo le debo una oportunidad a él. Adiós (Cuelga). Qué difícil ha sido, con lo bien que lo pasé... pero bueno, ya está.

\section{(Recuerda con cierta tristeza).}


Ayer, mientras tomábamos la cerveza en el bar del aeropuerto le conté a Javier, entre risas, lo de que había leído que una mujer ha intentado asfixiar a su marido apretándole la cabeza entre sus pechos, y que otra lo intentó envenenar con polvos en el ... ahí abajo, le dio una risa... Es que la cosa es graciosa. Entonces se me ocurrió, cariño, que yo podría hacer algo así, contigo. Claro que todavía no sabía que habías cambiado. Lo de las tetas ya está claro que no es posible, no me llegan, y lo del veneno, no sé, a la brasileña la descubrieron y además puede dar una infección ahí abajo que eso luego cuesta mucho curárselo y yo soy muy mía para mis partes. Así que se me ocurrió que... (Pausa. Se lo piensa). Si yo hubiera sabido que habías cambiado ni lo hubiera pensado, pero ya que estaba y con lo que pasó luego...

Y al final, voy y le digo, Javier he pensado hacerlo. ¡Asesinarlo! Dice Javier que la falta de presión no sólo me había excitado, que me había hecho perder la cabeza. Se reía hasta que vio que era en serio. Es verdad, ese avión me cambió por completo. Y en lugar de asustarse, Javier me dijo: Vamos a ver cómo lo hacemos. ¿No es increíble, cariño? ¡Qué decidido! Yo le digo: No puedo asfixiarlo entre mis tetas, porque no me llegan, ni tampoco envenenarlo con el cunilinguus porque yo para eso soy muy mía, así que he pensado asfixiarlo mientras le hago una felación. ¿Cómo? -Me dice Javier- Y yo voy y le digo: Con almendras. Y Javier, como tiene mucho sentido del humor, me pregunta si las iba a pelar antes, ¡las almendras! ¡No! ¡No! Le voy a masajear eso... el... la... el pene, con aceite del almendras, es alérgico. Una vez estuvo a punto de asfixiarse sólo por echarse un poquito en las manos, que las tenía muy secas y yo le dije, échate un poquito de aceite, cariño, y al momento se le inflamó la glotis y casi se ahoga ahí mismo. Así que si me embadurno las manos y los labios con aceite de almendras y voy ahí... Seguro que se morirá. Y así estábamos ayer Javier y yo, entre en broma y en serio, y vienes tú y me dices que has cambiado y claro, con lo de la psiquiatra y todo, digo, pues ya no te mato. ¿Entonces nos divorciamos? Te pregunto y tú me dices que no hace falta, que sólo te tengo que mirarte con otros ojos, como si fuera tu amante, pero oficial, sin terceras personas. Que tu terapeuta dice que eso ayudará a que me vuelvas a desear. Pero yo nunca he tenido un amante, excepto lo que ha pasado hoy en el avión, excepto eso que como no llegamos a consumar pues no creo que cuente, no sé cómo son los amantes... Tantas veces 
me has pedido perdón y luego has vuelto a hacer lo mismo. Y tú que ahora era distinto porque habías hecho terapia y me mirarías con otros ojos, con ojos de amante. Tanto tiempo sin decirte cariño de verdad y sin hacerte el amor, sólo soportando tus ataques salvajes en mi cuerpo sin fuerzas. Y anoche... Pero cuando estábamos amándonos de esa manera tan bonita vas y de pronto me das un puñetazo, muy fuerte, me dolió mucho porque no lo esperaba, ya no y me dijiste que eso era para que no volviera a volar en avión, entonces me di cuenta de que no habías cambiado. Ni amantes oficiales ni nada. Fíjate que casi me convenciste de que eras diferente, de que tu bigote no era Chevrón, era más suave y bonito y de que no me follabas, me hacías el amor. Hasta que me partiste la cara de nuevo. Entonces pensé que, aunque a Javier le había dicho que no podía, yo iba a hacerte un masaje en tu eso... con aceite de almendras, se terminó. Ni Javier, ni tú, ni nada. Quería estar sola, cariño. Me duele la boca, me duelen los dientes, me duele el cuello, me vuelve a doler el alma.

Ha sido una escena memorable, ¿cómo puedes ser tan bestia, cariño? Empecé a darte un masaje, primero despacio, y cada vez más rápido, apretándote con más fuerza y mirándote a los ojos, no me lo quería perder..., ya te tenía en mis manos, de ahí pasé a besarte, como nunca, estaba decidida. De pronto te pusiste muy rojo, empezaste a hacer ruidos raros y a pegar saltos en la cama, estos ya no eran de placer. Pensé en llamar a una ambulancia, me diste pena. Casi me arrepiento cuando te escuche gritar entre gruñidos de asfixia y dolor: “¿Qué me pasa? Me ahogo...” No te habías dado cuenta... Y entonces se me partió el corazón, quise alzarme y pedir socorro, pero no me dejaste. Casi a punto de asfixiarte, con la glotis incendiada, tuviste fuerza para engancharme del cuello hasta que conseguiste rompérmelo, ¿de dónde salió esa fuerza? Yo lo sé: del odio. Incluso muriéndote me matas. Entonces ya ni pude alcanzar el teléfono para llamar a la policía, o a Javier para pedir socorro. Tenía mi cabeza entre tus piernas y me apretabas terriblemente el cuello con ellas, yo intenté morderte la polla para que me soltaras, pero tus piernas me asfixiaban y con tus manos conseguiste arrancarme la cabeza y separarla de tu cuerpo. Todo eso mientras te ahogabas. Y ¿sabes lo peor? Creo que no llegaste a darte cuenta de lo del aceite. Creo que fue porque sí. Porque estabas enfadado y celoso. Creo que simplemente era eso, te apetecía hacerme daño. Otras veces la rabia te ha ahogado tanto 
como el aceite de almendras. Yo creo que no te diste ni cuenta de por qué no podías respirar. Y eso es lo peor. No te estabas defendiendo, me estabas matando sin razón. Y así es, has preferido matarme y morirte antes que dejarme viva y salvarte tú también. Si me hubieras permitido llamar a una ambulancia, total a mí me podrías haber estrangulado cualquier otro día... Lo de amantes oficiales era una idiotez, ya lo sabía yo, no aguantaste ni una hora esa farsa de la atracción que te había contado tu psiquiatra. No pudiste olvidar al marido Cabrón y convertirte en mi amante oficial. Estoy cansada de intentarlo, esta ha sido la última vez. Ojalá Javier gane el gran Hermano. Se lo merece (Se acuesta. Oscuro). 